\title{
Utilization of Modified Biosorbents Based on Walnut Shells in the Processes of Wastewater Treatment from Heavy Metal lons
}

\author{
Vita Halysh 1,2, ${ }^{1}$, Inna Trus , Mykola Gomelya1, Iryna Trembus', Bogdan Pasalskiy3, \\ Nadiia Chykun ${ }^{3}$, Ganna Trokhymenko ${ }^{4}$, Iryna Remeshevska ${ }^{5}$
}

1 Department of Ecology and Technology of Plant Polymers, Faculty of Chemical Engineering, Igor Sikorsky Kyiv Polytechnic Institute, Peremogy Avenu 37/4, 03056 Kyiv, Ukraine

2 Laboratory of Kinetics and Mechanisms of Chemical Transformations on the Surface of Solids, Department of Physico-Chemistry of Carbon Nanomaterials, O.O. Chuiko Institute of Surface Chemistry, National Academy of Sciences of Ukraine, General Naumov St. 17, 03164 Kyiv, Ukraine

3 Department of Commodity Science and Food Expertise, Kyiv national university of trade and economics, Kyoto str. 19, 02156, Kyiv, Ukraine

4 Department of Ecology and Environmental Technologies, Admiral Makarov National University of Shipbuilding, Heroiv Ukrainy ave., 9, 54025, Mykolaiv, Ukraine

5 Department of Environmental Chemistry, Admiral Makarov National University of Shipbuilding, Heroiv Ukrainy ave., 9, 54025, Mykolaiv, Ukraine

* Corresponding author's e-mail: v.galysh@gmail.com

\begin{abstract}
The problem of utilizing plant wastes of the agro-industrial complex is equally important and urgent. In this regard, it is advisable to develop a complex technology of plant waste application to solve the ecological problems of environmental pollution with heavy metals. Modification of walnuts shells with orthophosphoric acid has proven to be a promising process for obtaining the biosorbents with the efficient sorption properties. It was found out that the increase in the concentration of inorganic acid in modification time promotes the improvement in sorption capacity. Such biosorbents can be used in low-waste water demineralization systems. The utilization of waste biosorbents through the use in the composition of building materials is effective from an economic point of view. It was shown that the biosorbent acts as a fine additive; the increase in normal density and acceleration in hardening time takes place. At the same time, the compressive strength of the cement with the application of biosorbents decreases slightly. The results show that the modified walnuts shells have a slightly adverse effect on the hardening time of cement.
\end{abstract}

Keywords: spent biosorbent, utilization, building materials, low-waste technology

\section{INTRODUCTION}

Due to the prolonged growth of the anthropogenic load, environmental pollution occurs. This leads to pollution of all elements of the biosphere - the atmosphere, the lithosphere and, above all, the hydrosphere. Today, significant quantitative and qualitative changes in the water resources are taking place, which is caused by the discharge of insufficiently treated highly mineralized waters (Gomelya et al. 2014; Buzylo et al.,
2018). The content of organic substances, petroleum products and heavy metal ions exceeds the established standards. Heavy metals infiltrate to natural sources with the wastewaters from different industries. The discharge of untreated or insufficiently treated wastewaters, which contain a significant amount of heavy metal ions, causes an enormous damage to the environment, for instance, the functioning of activated sludge is disturbed, hydrobionts are significantly damaged, the ability of reservoirs for self-purification 
decreases (Malik et al. 2019; Vardhan et al. 2019; Banks et al. 2012).

Therefore, the creation of low-waste wastewater demineralization technologies and the removal of heavy metal ions is an extremely important task today, which will improve the quality of the treated water with a significant reduction in the amount of waste generated (Trus et al. 2019; Skiba \& Vorobyova 2019). The analysis of the literature data on the methods of wastewater purification from heavy metal ions showed that there are a large number of technological schemes based on the methods of reagent precipitation (Gomelya et al. 2014; Tian et al. 2019), ion exchange (Edebali and Pehlivan 2014; Fu et al. 2014;Gossuin et al. 2020), membrane methods (Ambiado et al. 2017; Gomelya et al. 2014), electrocoagulation (Oden and Sari-Erkan 2018; Chen et al. 2018; Xu et al. 2019), and sorption (Malovanyy et al. 2019; Mykhailenko N. et al. 2015; Sabadash et al. 2017; Gorobets \& Karpenko2017).

A very promising and economically feasible method for the removal of heavy metals from aqueous solutions is the biosorption with the use of inexpensive effective sorbents based on the waste or by-products after processing of plant materials (Halysh et al. 2018). The attractiveness of biosorbents application is associated with the cheapness and availability of raw materials for their production, as well as annual renewability. The sources of such raw materials include primary plant materials, such as timber, and secondary plant resources, that is, the waste from wood processing, agriculture, and the food industry. In general, the plant material is a biopolymer complex of polysaccharide and aromatic components containing different oxygen-containing functional groups. Scientists today are working in different directions to develop new effective ways of recycling these materials (Pereira et al. 2011; Novo et al. 2011; Deykun et al. 2018; The content of these components and their ratio determines the ability of plant material to participate in different chemical reactions, which determines the mechanisms of sorption processes (Halysh et al. 2019). Because of a low specific surface area, the efficiency of the sorption onto initial biomaterials is quite low. The suitable methods for increasing the absorption capacity of plant materials are grinding and chemical modification. By the chemical modification of plant wastes, it is possible to prepare effective sorbents with the desired surface properties and high sorption ability towards the heavy metal ions and radionuclides (Kartel and Galysh 2017). The use of the waste and by-products from agriculture and the food industry allows obtaining the sorbents for wastewater treatment and creating a fundamentally new scheme for their disposal.

One of the most promising ways for the disposal of the sludge formed through water treatment is their use in the composition of building materials (Trus et al. 2017). The sediments after water treatment can be used as the activators of cement hardening or can partially replace cement in the concrete (Breesem et al. 2014; Araujo et al. 2015; Krivenko P et al. 2018).

In order to create a complex low-waste technology of wastewater demineralization and purification from heavy metal ions, the paper defines the rational conditions for the utilization of waste biosorbents as additives in the production of building materials or fillers of polymeric materials used in construction.

The aim of the work was to investigate the effect of chemical modification of plant wastes of food industry with orthophosphoric acid into the properties of biosorbents and to study the effect of spent biosorbents addition on the properties of cement.

\section{MATERIALS AND METHODS}

Ground shells of walnuts (fraction with a particle size of $0.5-1.0 \mathrm{~mm}$ ) with a content of cellulose $41.2 \%$, lignin $37.5 \%$, resins, fats, waxes $5.2 \%$, mineral components $2.3 \%$ were used as a raw material.

The modification was carried out by the partial hydrolysis of walnut shells with $\mathrm{H}_{3} \mathrm{PO}_{4}$ at $15-75 \mathrm{wt} . \%$, at a solid to liquid ratio of $1: 5$, $100{ }^{\circ} \mathrm{C}$ for $60-180 \mathrm{~min}$ By the end of the phosphorylation, the samples of the lignocellulosic biosorbents were filtered, washed with distilled water to neutral $\mathrm{pH}$ and air-dried to a moisture content to 5-6 wt.\%.

The gravimetric method was applied to determine the yield of biosorbents. The absorption capacity of the starting material and modified materials towards methylene blue was determined under static conditions using a model solution with a dye concentration of $100 \mathrm{mg} / \mathrm{l}$. The process duration was $24 \mathrm{~h}$. The initial and equilibrium concentrations of sorbate were determined with the spectrophotometric method on a SPEKOL 11 spectrophotometer. The wavelength was $630 \mathrm{~nm}$. 
The studies of ion-exchange properties (static exchange capacity) of untreated and phosphorylated raw materials were determined by the amount of $\mathrm{Na}^{+}$sorption from $0.1 \mathrm{~N} \mathrm{NaOH}$ solution during $24 \mathrm{~h}$.

Initial and modified shells were also used as additives in the composition of cement. In order to investigate the effect of biosorbents present in the composition of cement on its properties, the cement of I/500 type was used for this purpose. The mineralogical composition of the cement is the following, wt. \%: $\mathrm{C}_{3} \mathrm{~S}-57.10, \mathrm{C}_{2} \mathrm{~S}-21.27$, $\mathrm{C}_{3} \mathrm{~A}-6.87, \mathrm{C}_{4} \mathrm{AF}-12.19$. The samples preparation was done by mixing all components in the ball mill for $20 \mathrm{~min}$. The samples were then tested for normal density, hardening time, compressive strength and distention (Fleysher et al. 2015).

\section{RESULTS AND DISCUSSION}

\section{Influence of $\mathrm{H}_{3} \mathrm{PO}_{4}$ concentration and time of modification on the biosorbent properties}

Table 1 shows the results of the study of sorption properties of lignocellulosic biosorbents, namely the efficiency of methylene blue removal from an aqueous solution and the static exchange capacity for $\mathrm{Na}^{+}$of starting and modified materials depending on the time of modification with $\mathrm{H}_{3} \mathrm{PO}_{4}$.

The results of the study show that the parameters of the modification significantly affect the biosorbent properties. The increase in the concentration of inorganic acid from 30 to $75 \%$ promotes a decrease in the yield of the final product. The same is observed with increasing the modification time. In spite of this, the sorption capacity is improving as the static exchange capacity for
$\mathrm{Na}+$ and efficiency of methylene blue removal increase throughout the investigated range. This can be explained by the fact that depolymerization of polysaccharide components take places in the process of modification the removal from the plant raw materials of extractive organic and inorganic substances, which leads to the formation of a porous structure in the phosphorylated lignocellulosic products, The absorption of the cationic dye on such sorbents occurs both due to the physical adsorption and by the mechanisms of chemical sorption with the participation of the functional groups of the modified material.

\section{The technological scheme of water treatment with the application of biosorbents}

On the basis of the obtained results, a complex technology of water demineralization can be proposed. The scheme for the wastewater treatment from heavy metal ions using biosorbents is presented in Figure 1.

The wastewater containing heavy metal ions enters the reservoir 1 , where, in case of presence of divalent iron ions, the air is supplied by the compressor. During intensive aeration, the oxidation of ferrous iron occurs to form insoluble ferric hydroxide, which is separated on a mechanical filter 2. From the mixer 3 wastewater enters the chamber for sorption purification 4 , where the special system 11 injects the required amount of biosorbent. The process is carried out at a constant stirring, which increases the efficiency of sorption. The purified water is separated from the waste sorbent in the separator 5 . The spent sorbent is dehydrated on the filter press 8 and dried in the dryer 9 . The dry sorbent is then can be utilized.

Table 1. Biosorbent yields and sorption properties

\begin{tabular}{|c|c|c|c|c|}
\hline \multirow[b]{2}{*}{$\begin{array}{c}\mathrm{H}_{3} \mathrm{PO}_{4} \text { concentration, } \\
\text { wt. } \%,\end{array}$} & \multirow{2}{*}{ Time of modification, } & \multicolumn{3}{|c|}{ Biosorbents characterization } \\
\hline & & $\begin{array}{l}\text { Yield, } \\
\%\end{array}$ & $\begin{array}{c}\text { Static exchange capacity } \\
\text { for } \mathrm{Na}^{+}, \\
\mathrm{mg}-\mathrm{eq} / \mathrm{g}\end{array}$ & $\begin{array}{c}\text { Efficiency of methylene } \\
\text { blue removal\% }\end{array}$ \\
\hline- & - & - & 1.48 & 39.2 \\
\hline \multirow{3}{*}{30} & 60 & 80.0 & 2.49 & 51.3 \\
\hline & 120 & 78.7 & 2.78 & 53.0 \\
\hline & 180 & 70.4 & 2.94 & 57.5 \\
\hline \multirow{3}{*}{50} & 60 & 77.1 & 2.94 & 55.3 \\
\hline & 120 & 70.6 & 3.29 & 69.3 \\
\hline & 180 & 65.6 & 3.33 & 80.1 \\
\hline \multirow{3}{*}{75} & 60 & 70.9 & 2.99 & 58.2 \\
\hline & 120 & 63.1 & 3.36 & 71.6 \\
\hline & 180 & 58.8 & 3.37 & 79.9 \\
\hline
\end{tabular}




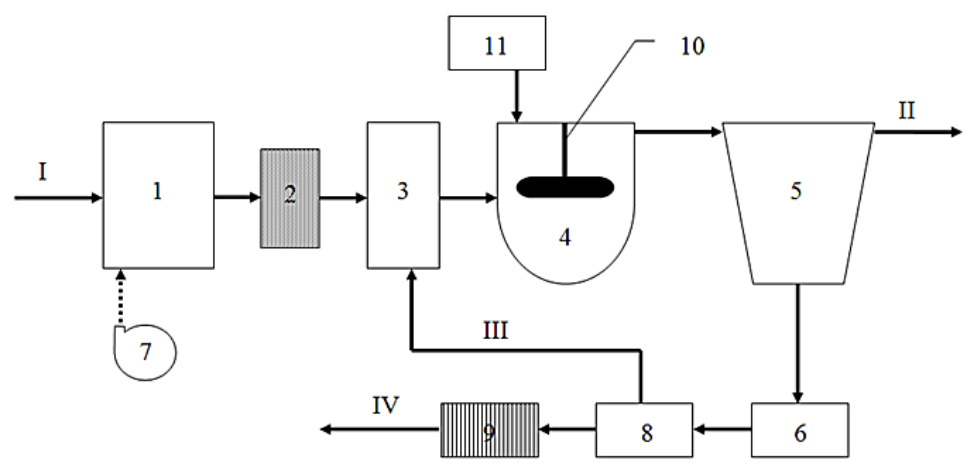

Fig. 1. Technological scheme for wastewater treatment from heavy metal ions using sorbents based on plant materials: I - wastewater; II - purified water; III - filtrate from the filter press; IV - dry sorbent for utilization

1 - collecting tank; 2 - mechanical filter; 3 - mixer; 4 - chamber for sorption purification; 5 - separator for separation of waste sorbent; 6 - waste sorbent collector; 7 - compressor for blowing air; 8 - filter press; 9 - dryer for waste sorbent; 10 - mixer; 11 - system of dosing and delivery of biosorbent

\section{Application of waste biosorbents as additives in the cement production}

While evaluating the effect of unmodified walnut shell on the physical and chemical properties of cement, it was established that the unmodified walnut shells play the role of a fine additive, that increases the normal density (on 6-19\%) and accelerates the hardening (2.0-2.5 times) as can be seen from Table 2. The increase in normal density takes place due to the fact that more water is needed to form adsorption water shells around
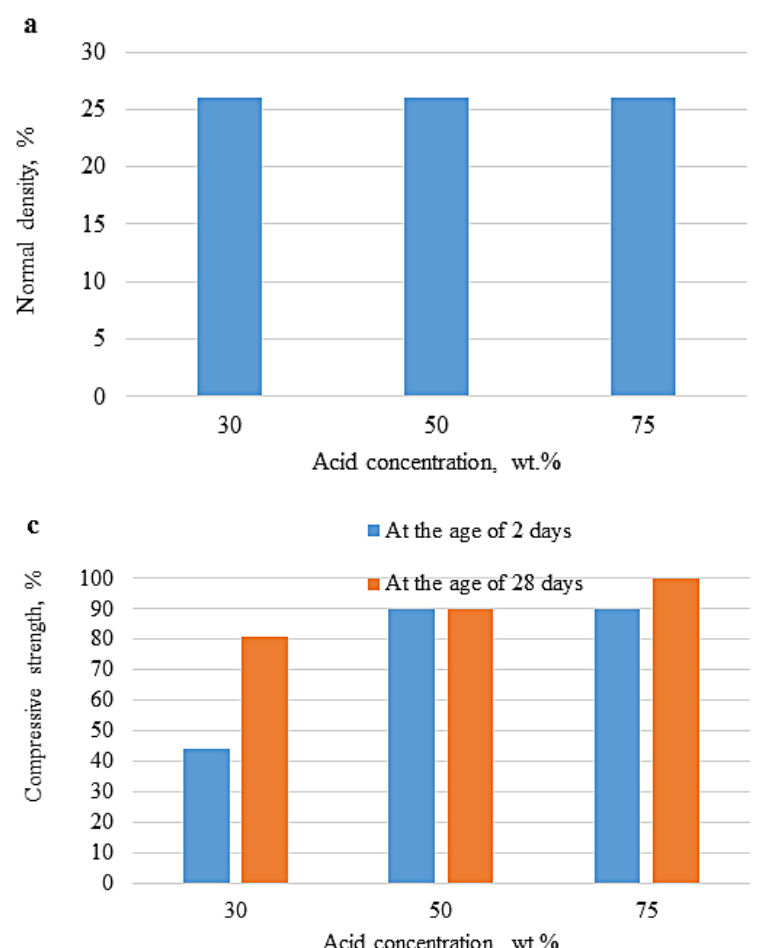

the fine particles of plant material. The higher the content of the shell, the more water is consumed to obtain a paste of normal density. The acceleration of hardening takes place due to the fact that the fine additive acts as a thickener (similar to clay).

The compressive strength of cement samples decreases with the increase in the walnut shells content but the effect is a minor. This can be explained by the increased normal density of the cement paste. The coefficient of water removal also increases, but not significantly (from $4 \%$ to $6 \%$ ),
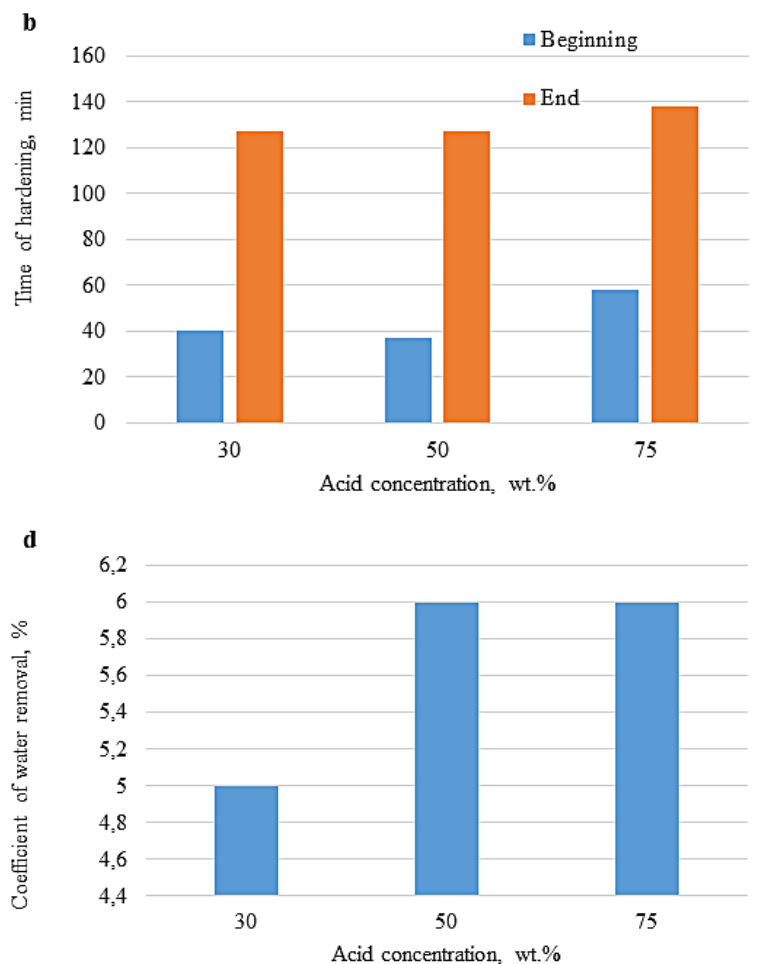

Fig. 2. Physical and mechanical properties of cement with the content of modified walnut shells $1.5 \%$ : $\mathrm{a}$ - normal density; $\mathrm{b}$ - hardening time; $\mathrm{c}$ - compressive strength; $\mathrm{d}$ - coefficient of water removal 
Table 2. The effect of walnut shawls content in the composition of cement on its properties

\begin{tabular}{|c|c|c|c|c|c|c|}
\hline \multirow{2}{*}{$\begin{array}{l}\text { Walnut shells } \\
\text { content, wt. \% }\end{array}$} & \multirow{2}{*}{$\begin{array}{c}\text { Normal } \\
\text { density, \% }\end{array}$} & \multicolumn{2}{|c|}{ Hardening time, $\min$} & \multicolumn{2}{|c|}{ Compressive strength, \% } & \multirow{2}{*}{$\begin{array}{c}\text { Coefficient of } \\
\text { water removal, } \\
\%\end{array}$} \\
\hline & & begging & end & $\begin{array}{l}\text { at the age of } \\
2 \text { days }\end{array}$ & $\begin{array}{c}\text { at the age of } 28 \\
\text { days }\end{array}$ & \\
\hline- & 24.0 & 62 & 140 & 100 & 100 & 4.1 \\
\hline 1 & 24.5 & 60 & 130 & 98 & 98 & 4.5 \\
\hline 3 & 27.1 & 45 & 90 & 68 & 95 & 6.0 \\
\hline 5 & 28.4 & 40 & 75 & 65 & 80 & 6.0 \\
\hline
\end{tabular}

and the increase in the content of the sells above $3 \%$ does not lead to any changes in values.

The influence of adding of $1.5 \%$ of modified walnut shell on the physicochemical properties of cement is shown in Figure 2. The samples of biosorbents obtained during the walnut shells modification with $\mathrm{H}_{3} \mathrm{PO}_{4}$ of different concentration over $120 \mathrm{~min}$, were chosen for further investigations.

The data in Figure 2 show that the impact of the modified walnut shells on normal density is quite insignificant if compared to the initial material. It is also obvious, that the acid modification of shells leads to a decrease in the beginning of hardening of cement due to the higher lignin content. The compressive strength increases in all cases due to the fact that lignin shows good binding properties. The coefficient of water removal changes insignificantly in comparison with the initial material.

Thus, taking into account the positive effect of adding the shells on the physicochemical properties of the cement, it can be recommended to use this fact in the development of an effective method of its utilization through the application in cement production in quantity of $1-3 \%$.

\section{CONCLUSIONS}

1. In this paper, the efficiency of walnut shells modification with $\mathrm{H}_{3} \mathrm{PO}_{4}$ at $15-75$ wt.\%, at a solid to liquid ratio of $1: 5,100^{\circ} \mathrm{C}$ and during 60-180 min was studied.

2. It was shown that the sorption properties of the obtained materials greatly depend on the parameters of plant wastes modification.

3. The technological scheme for the wastewater treatment from the heavy metal ions with the application of biosorbents and the way of waste sorbents utilization was proposed.

4. It was found out that the shells act as a fine additive, which increases the normal density and accelerates the hardening time. The compressive strength of the cement samples with the application of lignocellulosic materials decreases slightly.

5. The results show that phosphoric acid, which has been used to modify the plant waste to increase their sorption capacity, has a slightly adverse effect on the hardening time of cement.

\section{REFERENCES}

1. Gomelya N.D., Trus I.N., \&Nosacheva Y.V. 2014. Water purification of sulfates by liming when adding reagents containing aluminum. Journal of Water Chemistry and Technology, 36(2), 70-74.

2. Buzylo V., Pavlychenko A., Savelieva T., Borysovska O. 2018. Ecological aspects of managing the stressed-deformed state of the mountain massif during the development of multiple coal layers. Paper presented at the E3S Web of Conferences, 60.

3. Malik L.A., Bashir A., Qureashi, A., Pandith, A.H. 2019. Detection and removal of heavy metal ions: A review. Environmental Chemistry Letters, 17(4), 1495-1521.

4. Vardhan K.H., Kumar P.S., Panda R.C. 2019. A review on heavy metal pollution, toxicity and remedial measures: Current trends and future perspectives. Journal of Molecular Liquids, 290.

5. Banks J.L., Ross D.J., Keough M.J., Eyre B.D., Macleod C. K. 2012. Measuring hypoxia induced metal release from highly contaminated estuarine sediments during a 40day laboratory incubation experiment. Science of the Total Environment, 420, 229-237.

6. Trus I., Radovenchyk I., Halysh V., Skiba M., Vasylenko I., Vorobyova V., Hlushko O., Sirenko L. 2019. Innovative approach in creation of integrated technology of desalination of mineralized water. Journal of Ecological Engineering, 20(8), 107-113.

7. Skiba M. I., Vorobyova V. 2019. The plasma-chemical formation of polysorbate 80-coated silver nanoparticles and composite materials for water treatment. Pigment and Resin Technology, 48(5), 431-438.

8. Gomelya M., Trus I., Shabliy T. 2014. Application of aluminium coagulants for the removal of sulphate from mine water. Chemistry and Chemical Technology, 8(2), 197-203. 
9. Tian Z., Zhang L., Ni C. 2019. Preparation and flocculation properties of modified alginate amphiphilic polymeric nano-flocculants. Environmental Science and Pollution Research, 26(31), 32397-32406.

10. Edebali S., Pehlivan E. 2014. Evaluation of cr(III) by ion-exchange resins from aqueous solution: Equilibrium, thermodynamics and kinetics. Desalination and Water Treatment, 52(37-39), 7143-7153.

11. Fu L., Shuang C., Liu F., Li A., Li Y., Zhou Y., Song H. 2014. Rapid removal of copper with magnetic poly-acrylic weak acid resin: Quantitative role of bead radius on ion exchange. Journal of Hazardous Materials, 272, 102-111.

12. Gossuin Y., Hantson A., Vuong Q.L. 2020. Low resolution benchtop nuclear magnetic resonance for the follow-up of the removal of $\mathrm{Cu} 2+$ and $\mathrm{Cr} 3+$ from water by amberlite IR120 ion exchange resin. Journal of Water Process Engineering, 33.

13. Ambiado K., Bustos C., Schwarz A., Bórquez R. 2017. Membrane technology applied to acid mine drainage from copper mining. Water Science and Technology, 75(3), 705-715.

14. Gomelya M.D., Trus I.M., Radovenchyk I.V. 2014. Influence of stabilizing water treatment on weak acid cation exchange resin in acidic form on quality of mine water nanofiltration desalination. Naukovyi Visnyk Natsionalnoho Hirnychoho Universytetu, 5, 100-105.

15. Oden M.K., Sari-Erkan H. 2018. Treatment of metal plating wastewater using iron electrode by electrocoagulation process: Optimization and process performance. Process Safety and Environmental Protection, 119, 207-217.

16. Chen X., Ren P., Li T., Trembly J.P., \& Liu X. 2018. Zinc removal from model wastewater by electrocoagulation: Processing, kinetics and mechanism. Chemical Engineering Journal, 349, 358-367.

17. Xu T., Zhou Y., Lei X., Hu B., Chen H., \& Yu G. 2019. Study on highly efficient cr(VI) removal from wastewater by sinusoidal alternating current coagulation. Journal of Environmental Management, 249.

18. Malovanyy M., Sakalova H., Vasylinycz T., Palamarchuk O., Semchuk J. 2019. Treatment of effluents from ions of heavy metals as display of environmentally responsible activity of modern businessman. Journal of Ecological Engineering, 20(4), 167-176.

19. Mykhailenko N., Makarchuk O., Dontsova, T., Gorobets S., Astrelin I. 2015. Purification of aqeous media by magnetically operated saponite sorbents. Eastern-European Journal of Enterprise Technologies, 4(10), 13-20.

20. Sabadash V., Mylanyk O., Matsuska O., \& Gumnitsky J. 2017. Kinetic regularities of copper ions adsorption by natural zeolite. Chemistry and Chemical Technology, 11(4), 459-462.

21. Gorobets S. and Karpenko Y. 2017. The development of a magnetically operated biosorbent based on the yeast saccharomyces cerevisiae for removing copper cations $\mathrm{Cu} 2+$. Eastern-European Journal of Enterprise Technologies, 1(6-85), 28-34.

22. Halysh V., Sevastyanova O., Riazanova A. V., Pasalskiy B., Budnyak T., Lindström M. E., Kartel M. 2018. Walnut shells as a potential low-cost lignocellulosic sorbent for dyes and metal ions. Cellulose, 25(8), 4729-4742.

23. Pereira P.H.F., Voorwald H.C.J., Cioffi M.O.H., Mullinari D.R., Da luz S.M., Da silva M.L.C.P., 2011. Sugarcane bagasse pulping and bleaching: thermal and chemical characterization. BioResources. 6(3), 2471-2482.

24. Novo L.P., Gurgel L. V.A., Marabezi K., da SilvaCurvelo A.A., 2011. Delignification of sugarcane bagasse using glycerol-water mixtures to produce pulps for saccharification. Bioresour. Technol. 102(21), 10040-10046.

25. Deykun I., Halysh V., Barbash V. 2018. Rapeseed straw as an alternative for pulping and papermaking. Cellulose Chemistry and Technology, 52(9-10), 833-839

26. Halysh V., Sevastyanova O., De Morais D., Riazanova A., Lindström M.E., Gomelya M. 2019. Effect of oxidative treatment on composition and properties of sorbents prepared from sugarcane residues. Industrial Crops and Products, 139(1), 111566.

27. Kartel, M., Galysh, V., 2017. New composite sorbents for caesium and strontium ions sorption. Chemistry Journal of Moldova. 12(1), 37-44.

28. Trus I.M., Fleisher H.Y., Tokarchuk V.V., Gomelya M.D., Vorobyova V.I. 2017. Utilization of the residues obtained during the process of purification of mineral mine water as a component of binding materials. Voprosy Khimii i Khimicheskoi Tekhnologii, (6), 104-109.

29. Breesem K.M., Faris F.G., Abdel-Magid I.M. 2014. Reuse of alum sludge in construction materials and concrete works: a general overview. Infrastucture university Kuala Lumpur research journal, 2 (1), 20-30.

30. Araujo F., Scalize P., Lima J., Vieira N., Albuquerque A., Santos I. 2015. Soil-cement floor produced with alum water treatment residues. International journal of civil and environmental engineering, 9 (3), 377-380.

31. Krivenko P., Kovalchuk O., Pasko A. 2018. Utilization of industrial waste water treatment residues in alkali activated cement and concretes. Key engineering materials, 761, 35-38. 